\title{
ARM SPAN AND KNEE HEIGHT AS PREDICTORS OF STATURE AMONG PERADENIYA MEDICAL STUDENTS
}

\author{
Varun R, Jayasinghearachchi T.M.K*, Priyalini R, M.D.P. Gunasena \\ Faculty of Medicine University of Peradeniya
}

*Corresponding author: dudevraj@yahoo.co.in

Key words: Stature, Arm span, Knee height, Predictors of Height

\begin{abstract}
Background:
The Stature or height is one of the most used anthropometric measurements in clinical medicine for the calculation of many parameters. When the accurate measurement for stature is unobtainable, other surrogates are used to predict stature. Arm span and knee height are proven to be reliable predictors of stature in such circumstances. Inter and intra population variations may be observed in relation to anthropometry due to factors such as genetic makeup, age, gender and ethnicity. Though many Asian races have been studied in relation to these parameters, similar studies were not reported among any ethnic group or age group in Sri Lanka. Thus the aim of the present study was to analyze the correlation between stature and two anthropometric variables; the arm span and knee height of young Sinhalese medical students of University of Peradeniya, Sri Lanka, and to predict the best.
\end{abstract}

\begin{abstract}
Methods:
Young Sinhalese medical students were selected randomly and stature, arm span and knee height were measured using standard anthropometric techniques. Pearson's coefficients of correlation and regression equations were calculated using SPSS statistical package between stature and the two anthropometric variables.

Results:

A total of 196 Sinhalese medical students (101 male, 95 females) of 20-26 years of age were studied. The arm span showed a strong significant linear correlation(r) with stature $\left(\mathrm{r}=0.832, \mathrm{r}^{2}=0.692 ; \mathrm{r}=0.879, \mathrm{r}^{2}=0.773, \mathrm{p}=0.000\right.$.for males and females respectively) while knee height too has shown a similar relationship. $\left(r=0.740, r^{2}=0.0548 ; r=0.668, r^{2}=0.446\right.$, $\mathrm{p}=0.000$. for males and females respectively) However arm span correlates best with the stature in this study group. Following equations were derived to predict the stature $(\mathrm{Y})$. In males $\mathrm{Y}=48.801+0.6784$ Arm span, and $\mathrm{Y}=73.945+1.784$ Knee height, in females $\mathrm{Y}=47.451+0.678$ Arm Span and $\mathrm{Y}=95.427+1.249$ Knee height.
\end{abstract}

\section{Conclusion:}

Arm span is the best parameter to predict stature for both genders of young Sinhalese medical students of University of Peradeniya, Sri Lanka.

Stature is the maximum distance measured from the point where the heel touches the floor to the highest point of the head while the person is in erect position ${ }^{1}$. It is an easily measured and widely used anthropometric parameter in clinical medicine and in field of scientific research, such as calculation of $\mathrm{BMI}^{2}, \mathrm{BMR}$, and Creatinine Height index ${ }^{2,3}$ and for interpretation of lung function tests. It is also used as an indicator of nutritional status ${ }^{2}$

The measurement of stature is either not possible or not accurate in situations where patients cannot assume the posture necessary for the accurate measurement. This difficulty may be encountered in critically ill patients who are monitored in ICU where many indexes are calculated using height ${ }^{2}$, Arm span and knee height are two such anthropometric variables proven by many (a) studies and used commonly at present ${ }^{2,3,5}$. 
Arm span is the maximum distance between tips of the longest fingers of both hands while the person extends both arms at the level of the shoulders ${ }^{1}$. Knee height is defined as the length measured parallel to the long axis of the tibia from the heel of the foot to anterior surface of the thigh while ankle and knee are bent at a $90^{\circ}$ angle ${ }^{1}$. It has an additional advantage as it could be measured while patient is seated or even lying down ${ }^{1,6}$.

Therefore arm span and knee height could be used alternatively to predict the stature. Nevertheless it is important to know the best anthropometric measurement when both parameters could be used. Studies have shown that all these anthropometric parameters are being influenced by many genetic, environmental and biological factors ${ }^{2,3,5}$. Africans and Caucasians have a large body frame than Asians while males of all ethnicities have higher values than their female counterparts. Many studies have proven these associations. It is proven that a person's growth in height ceases at the chronological age of 19years and after the age of 30 years onwards age related regressions take place $3,7,8$. Thus equations derived to predict stature using arm span and knee height is influenced by factors such as ethnicity age and gender 5 .

Different ethnic groups in Sri Lanka may account for a different anthropometry and it demands similar studies among them to develop regression equations using arm span and knee height to estimate stature.

The present study is aimed at analysis of correlation between height and two anthropometric variables; the arm span and knee height of young Sinhalese medical students of University of Peradeniya, Sri Lanka, and developing regression equations for each category.

\section{Materials \& Methods}

The study is a descriptive correlational study of stature, arm span and knee height of healthy Sinhalese medical students of the Faculty of Medicine, University of Peradeniya which was conducted throughout a period of two months from January to March in 2010.
Ethical clearance for the study was granted by the Ethical Clearance Committee of the Faculty of Medicine, University of Peradeniya.

Students were randomly selected to be included in this study. Informed verbal consent was obtained. Students possessing skeletal deformities, physical disabilities, past history of skeletal injuries or diseases affecting bones and joints and students who cannot stand erect, who cannot bend their knee and who are on any form of hormonal medications were excluded. Students whose ancestors are not Sinhalese or mixed ethnic marriages within previous three generations were also excluded. Stature, arm span and knee height was measured using a device made by the researchers. This instrument incorporated the principles of a stadiometer, knee height caliper and principles of measurement of arm span ${ }^{1}$. It consists of a vertical ruler with two self retaining horizontal sliders to measure the stature and the knee height, and a horizontal ruler sliding on two vertical poles to adjust against the subject's shoulders and measure arm span. These were made of wood steel and commercially available steel measuring tapes. All the measurements were done according to standard measuring techniques ${ }^{1}$ by well trained investigators. Knee height was measured in the sitting position using a height adjustable chair.

All measurements were performed thrice and the mean value was obtained. Statistical analysis was in SPSS 10 statistical package using Simple Linear Regression analysis and Pearson coefficients of correlation were calculated for stature and knee height and for stature and arm span. Prediction equations were then developed subsequently.

\section{Results}

The study population consisted of 196 subjects of 20 to 26 years (101 males and 95 females). Stature, knee height and arm span measurements are shown in tables 1 and 2 . 
Table 1 Physical measurement of males.

\begin{tabular}{|l|l|l|l|}
\hline \multirow{2}{*}{ Variables } & \multicolumn{2}{|l|}{ Male } \\
\cline { 2 - 4 } & Mean & $\begin{array}{l}\text { Standard } \\
\text { Deviation }\end{array}$ & Range \\
\hline Age (years) & 23.08 & 1.4675 & $20-26$ \\
\hline Stature $(\mathrm{cm})$ & 168.03 & 5.4320 & $153.7-180.5$ \\
\hline Arm span $(\mathrm{cm})$ & 174.35 & 6.6099 & $157.5-189.3$ \\
\hline Knee height $(\mathrm{cm})$ & 52.75 & 2.2541 & $47.1-58.8$ \\
\hline
\end{tabular}

Table 2 Physical measurement of females.

\begin{tabular}{|l|l|l|l|}
\hline \multirow{2}{*}{ Variables } & \multicolumn{3}{|l|}{ Female } \\
\cline { 2 - 4 } & Mean & $\begin{array}{l}\text { Standard } \\
\text { Deviation }\end{array}$ & Range \\
\hline Age (years) & 23.95 & 1.2913 & $20-26$ \\
\hline Stature $(\mathrm{cm})$ & 156.06 & 5.5453 & $145.3-172.5$ \\
\hline Arm span $(\mathrm{cm})$ & 160.30 & 7.1979 & $145.2-185.0$ \\
\hline Knee height $(\mathrm{cm})$ & 48.54 & 2.9651 & $42.1-58.8$ \\
\hline
\end{tabular}

Figure 2 Regression of stature and knee

height of males.

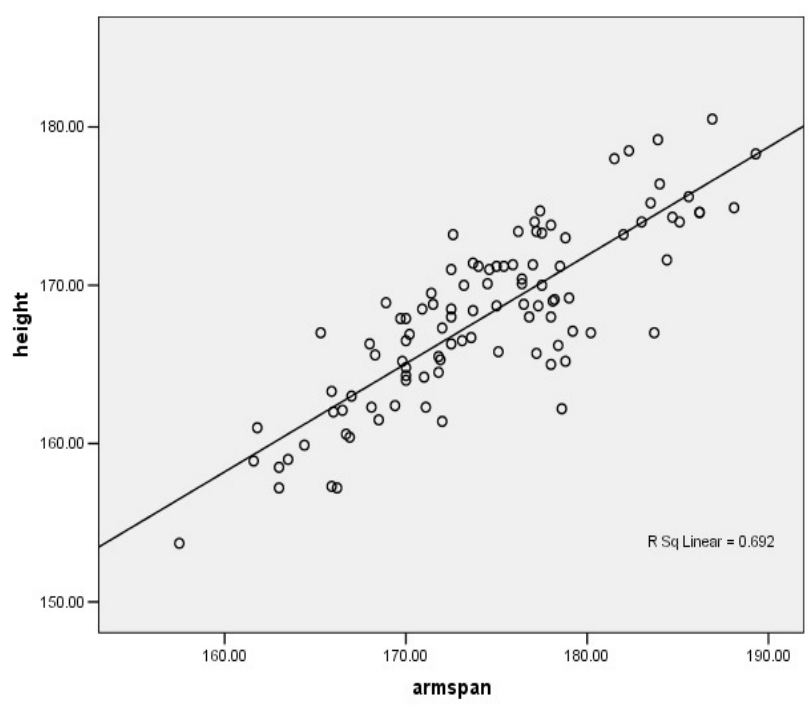

coefficients were 0.832 and 0.879 for males and females respectively

In both genders mean arm span is higher than the mean stature. In females the mean difference is 3.7 $\mathrm{cm}$ while in males it is $6.32 \mathrm{~cm}$. A highly significant correlation between stature and arm span was observed in both genders and Pearson's correlation.
Figure 1 Regression of arm span and stature of males

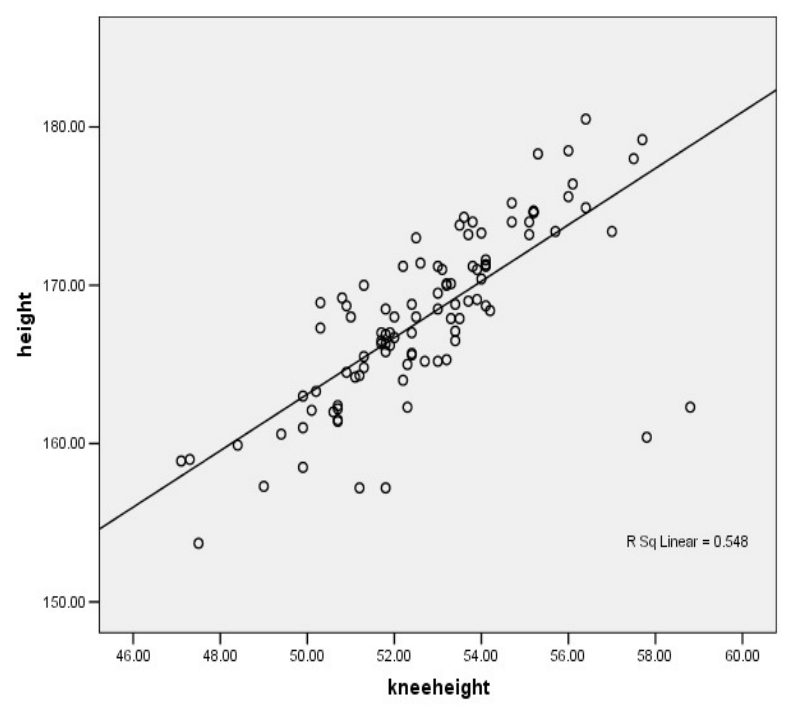




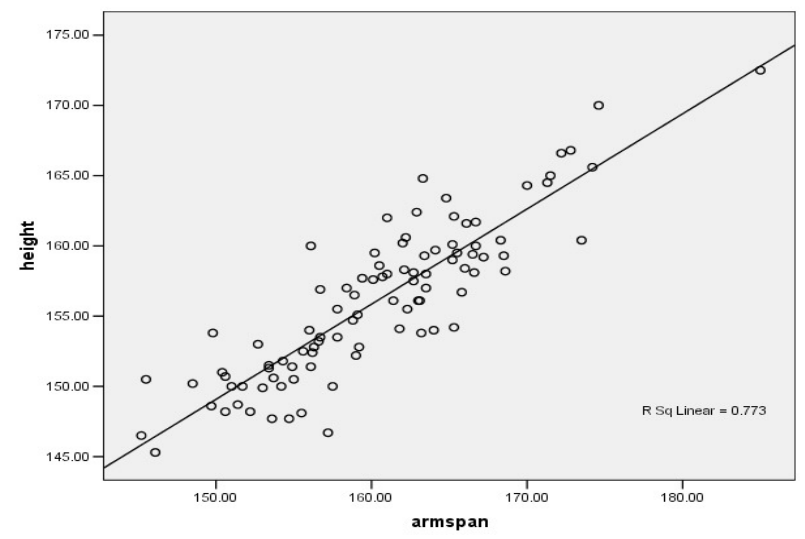

Figure 3 Regression of arm span and stature of females

A similar correlation was obtained between the stature and knee height. Pearson correlation coefficients for the latter were 0.740 and 0.668 for males and females respectively.

In males $69.2 \%$ and in females $77.3 \%$ of the variance of stature has been explained by the regression models developed using arm span. In contrast only $54.8 \%$ of the variance of stature in males and $44.6 \%$ in females have been explained by the model using knee height.

\section{Discussion}

When the accurate measurement for stature is unobtainable, it is computed using other surrogates. Arm span and knee height are the most widely used. This study analyses the correlation coefficients of stature and arm span and stature and knee height of a group of Sinhalese medical students of $20-26$ years in Sri Lanka. Regression equations are hence developed to predict stature.

The major determinants of one's height are the length of the long bones and the height of the vertebral column. At the time of fusion of long bones and completion of growth of the vertebral column the maximum stature is achieved. This skeletal growth stops at the age of 18 to 20 years ${ }^{3,7,12}$. After achieving maximum stature the bones are in relatively static period up to 40 years of age after which

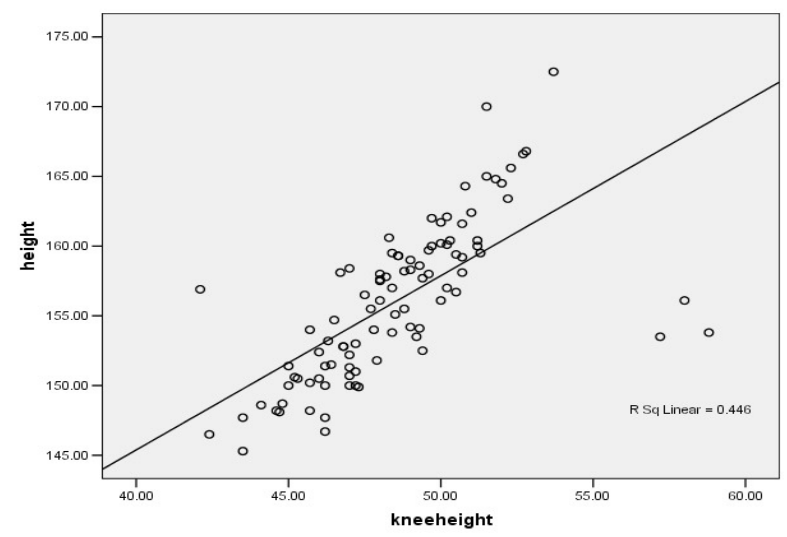

Figure 4 Regression of knee height and stature of females

the natural process of senile degeneration takes place ${ }^{7}$. Some researchers have stated that there may be certain degree of independence between age and knee height ${ }^{15}$.

It is observed that the males generally have higher anthropometric measurement than that of females in the present study. Similar observations are made in many studies ${ }^{2,8,9,10}$. These differences may be due to gender associated genetic factors, hormonal factors and lifestyle factors ${ }^{2}, 8,9,10$.

In the present study the difference in the arm span and height of the female group was $3.7 \mathrm{~cm}$, and this observation is in line with a study by Mohanty et $a l^{3}$ where he studied a group of South Indian females of ages 20 to 26 years and obtained a difference of $2.5 \mathrm{~cm}$. Similarly Steel and Chenier's study ${ }^{11}$ found $8.3 \mathrm{~cm}$ and $3.3 \mathrm{~cm}$ for Black and White females respectively.

Mohanty et $a l^{3}$, Shahar \& Pooy $^{4}$, Zevrev \& $\mathrm{Chisi}^{13}$ and Fatmah $^{8}$ have shown significant strong positive linear relationships between arm span and stature. Similar higher correlations were shown in the present study too. Thus it is clearly evident that the arm span can be used as the predictor of stature, but it should be borne in mind that ethnic specific equations should be derived for a specific ethnicity $^{2,3,5}$. 
In the present study knee height too showed a positive linear relationship with height ( $\mathrm{r}=0.740$ for males \& 0.668 for females) while Li et $a l^{12}$, Shahar \& Pooy ${ }^{4}$ and Fatmah ${ }^{8}$ showed a better correlation between these parameters in their studies. This contradiction may be mainly due to the variations in mean ages of above study groups, and subsequently to ethnicity of study groups and other environment based factors of growth ${ }^{3,8}$. This hypothesis is also favoured by a study conducted by Nunez ${ }^{5}$.

In the present study it is evident that the arm span is superior to knee height in predicting stature as the age group studied has not yet started age related regression. Similar findings were observed by Shahar \& $\operatorname{Pooy}^{4}(\mathrm{r}=0.81$ for males \& 0.84 for females) although the mean age of the study group was 42.3 years.

\section{Conclusion}

The best parameter to predict stature is the arm span for both genders of Sinhalese medical students aged 20 to 26 years in University of Peradeniya Sri Lanka.

Regression equations derived to predict stature are,

Stature $_{\text {Males }}(\mathrm{cm})=48.801+0.6784$ AS $(\mathrm{cm})$

Stature $_{\text {Females }}(\mathrm{cm})=47.451+0.678$ AS $(\mathrm{cm})$

Stature $_{\text {Males }}(\mathrm{cm})=73.945+1.784 \mathrm{KH}(\mathrm{cm})$

Stature $_{\text {Females }}(\mathrm{cm})=95.427+1.249 \mathrm{KH}(\mathrm{cm})$

\section{References}

1. Lohman TG, Roche AF, Mattorell R 1988, 'Segment Length', Anthropometric Standardization Reference Manual, Human Kinetics Publishers Inc, Illinois, pp18-20.

2. Food and Nutrition Research Institute Philippines 1998, 'Arm Span and Knee height As Proxy Indicators for Height', $5^{\text {th }}$ National Nutritional Survey, DOST, Mannilla.

3. Mohanty SP, Suresh B, Sreekumaran N 2001, 'The use of arm span as a predictor of height: a study of South Indian women', journal of Orthopaedic Surgery, 9, 19-23.

4. Shahar S, Pooy NS 2003, 'Predictive equations for estimation of stature in Malaysian elderly people', Asia Pacific Journal of Clinical Nutrition, 12: 1, 80-84.

5. Nunez VMM, Rodriguez MAS, Sandoval AC 2002 'Equations for Predicting height for Elderly Mexican Americans Are Not Applicable for elderly Mexicans', American Journal of Human Biology, 14: 351-355.

6. Chumlea WC, Roche AF, Stienbaugh MI 1985, 'Estimating stature from knee height for persons 60-90 years of age', Journal of American Geriatric Society, 33:116-120.

7. Reddy KSN 2006, 'Identification', The Essentials of Forensic Medicine, $25^{\text {th }}$ edition, Suguna Devi, Hyderabad, 50-86.

8. Fatmah M 2009, 'Predictive equations for estimation of stature from knee height, arm span and sitting height in Indonesian Javanese elderly people', International Journal of Medicine and Medical Sciences, 1: 456-461.

9. Chumlea WC, Guo S, Wholihan K 1998, 'Stature prediction equations for elderly nonHispanic white, non-Hispanic black and Mexican-American persons developed from NHANES III data',Journal of American Dietary association, 98:137-142

10. Li ETS, Tang EKY, Wong CYM, Lui SSH, Chan VYN, Dai DLK 2000, 'Predicting stature from knee height in Chinese elderly subjects', Asia Pacific Journal of Clinical Nutrition, 9: 4: 252-255.

11. Steele MF\& Chenier TC 1990, 'Arm-span, height, and age in Black and White women', Annals of Human Biology, 17:533-541.

12. Fogelman I, Bessent R 1982, 'Age Related Alterations in Skeletal Metabolism- 24 hour Whole-Body Retention of Diphosphonate in 250 normal subjects', Journal of Nuclear Medicine, 23,4:296-300.

13. Zverev YP, Chisi J 2005, 'Relationship between arm span and stature in Malawian children', College of Anthropology, 2: 469473.

14. Hickson M, Frost GA 2003, 'Comparison of three methods for estimating height in the acutely ill elderly population', Journal of Human Nutrition and Diet, 16, 13-20.

15. Zhang H, Hsu-Hage BH, Wahlqvist ML 1998, 'The use of knee height to estimate stature in elderly Chinese', Journal of Nutrition Health and Aging, 2: 2: 84-87. 